\title{
Effects of pair-feeding and growth hormone treatment on obese transgenic rats
}

Yasufumi Furuhata, Keiji Hirabayashi, Tomohiro Yonezawa, Michio Takahashi ${ }^{1}$ and Masugi Nishihara

Department of Veterinary Physiology, Veterinary Medical Science, University of Tokyo, 1-1-1 Yayoi, Bunkyo-ku, Tokyo 113-8657, Japan and ${ }^{1}$ Ajinomoto Co., Inc., Kawasaki 210-0801, Japan

(Correspondence should be addressed to M Nishihara; Email:amnishi@mail.ecc.u-tokyo.ac.jp)

\begin{abstract}
Background: It has been shown that GH-deficient subjects tend to have fat accumulation. We have produced human GH (hGH) transgenic rats that exhibit low circulating hGH levels and hyperphagia. These rats are also characterized by severe obesity, hyperinsulinemia and hyperlipidemia.

Objective: The present study was conducted in order to elucidate how excess caloric intake and impaired GH secretion account for fat accumulation and metabolic abnormalities in the transgenic rats.

Design and Methods: The transgenic rats were subjected to either pair-feeding with non-transgenic controls or hGH treatment from 4 to 12 weeks of age, and the effects on fat accumulation and some metabolic parameters were assessed.

Results: At the age of 12 weeks, body weight and food intake were greater in transgenic than in control rats by $10 \%$ and $27 \%$ respectively. The ratio of epididymal white adipose tissue weight to body weight (WAT/BW) was more than three times greater in transgenic than in control rats. Although pair-feeding for 8 weeks decreased body weight, it did not affect the WAT/BW ratio. Treatment with hGH affected neither body weight nor food intake, while it reduced the WAT/BW ratio by $30 \%$. Serum concentrations of triglyceride, free fatty acid, insulin and leptin were all significantly higher in the transgenic than in the control rats. Pair-feeding decreased serum triglyceride, insulin and leptin levels, but not serum free fatty acid levels. On the other hand, hGH treatment decreased only serum leptin concentrations.

Conclusions: These results suggest that severe fat accumulation in the transgenic rats mainly resulted from the decreased lipolytic action of $\mathrm{GH}$, while metabolic abnormalities mainly resulted from excess caloric intake.
\end{abstract}

European Journal of Endocrinology 146 245-249

\section{Introduction}

It is widely recognized that growth hormone (GH) is an endocrine regulator of protein synthesis and lipolysis as well as of skeletal bone growth $(1,2)$. Recently, evidence that obesity is associated with decreased $\mathrm{GH}$ levels has been accumulating. This evidence has shown that GH-deficient (GHD) subjects have an increased body fat mass, which can be reduced by GH therapy (1-4) and that $\mathrm{GH}$ has beneficial effects on obese (5) and obese diet-restricted subjects (6). In addition, GHD rats and transgenic mice expressing mutant GH exhibit not only dwarfism but also fat accumulation (7). Obesity develops ultimately under conditions in which energy intake and expenditure are unbalanced. In fact, increased food intake has been demonstrated in several obese animal models including ob/ob and $\mathrm{db} / \mathrm{db}$ mice (8). Interestingly, the circulating GH levels of these animals are suppressed (9-11), which may also account for their fat accumulation.

We have previously demonstrated that the transgenic rats we produce, which carry the chimeric gene for whey acidic protein promoter and human $\mathrm{GH}(\mathrm{hGH})$ genomic DNA, develop severe obesity. The transgenic rats are characterized by relatively low levels of serum hGH and by hyperinsulinemia and hyperlipidemia. Since the treatment of these rats with hGH for 1 week restored their phenotype at least partially (12), they are regarded as a useful model for analyzing how an impaired GH secretory pattern induces obesity. We have further shown recently that they exhibit hyperphagia as early as the age of 4 weeks (1 week after weaning) along with leptin resistance, which probably results from the suppression of leptin transport from the blood to the cerebrospinal fluid (13). 
Thus it is clear that both impaired GH secretion and increased caloric intake coexist in our transgenic rats.

The present study was undertaken in order to elucidate how energy imbalance and impaired GH secretion are involved in fat accumulation and metabolic abnormalities in transgenic rats. For this purpose, we utilized a pair-feeding paradigm and chronic GH replacement. Specifically, transgenic rats were subjected to either pair-feeding with non-transgenic controls or hGH treatment from 4 to 12 weeks of age, and the effects on body weight and adipose tissue mass were evaluated. The effects on serum triglyceride, free fatty acid (FFA), insulin and leptin concentrations were also determined.

\section{Materials and methods}

\section{Animals}

Generation of the hGH transgenic rats has been described previously (14). In this experiment, male
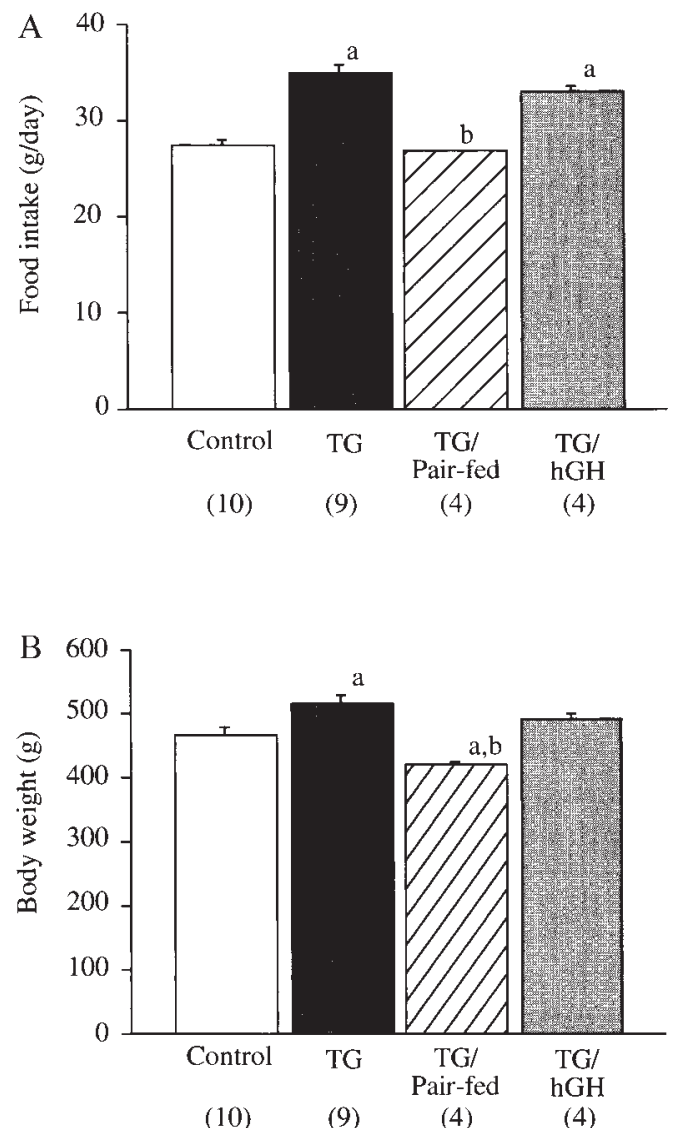

Figure 1 Food intake $(A)$ and body weight $(B)$ in control (Control), intact transgenic (TG), and pair-fed (TG/Pair-fed) and hGH-treated $(\mathrm{TG} / \mathrm{hGH})$ transgenic rats. Numbers of animals used are given in parentheses. Data are expressed as means and S.E.M. ${ }^{\mathrm{a}} P<0.05$ vs control; ${ }^{\mathrm{b}} P<0.05$ vs $\mathrm{TG}$. transgenic rats (heterozygotes) and their normal male littermates were used. After being weaned from the mother at 3 weeks of age, they were individually housed with free access to laboratory chow and water. They were kept under a constant room temperature $\left(23 \pm 1^{\circ} \mathrm{C}\right)$ and lighting schedule $(12 \mathrm{~h}$ light: $12 \mathrm{~h}$ darkness; lights on at $0700 \mathrm{~h}$ ).

\section{Experimental procedures}

The transgenic rats were subjected to either pair-feeding or hGH treatment from the age of 4 weeks. A group of transgenic rats were pair-fed the amount of food consumed by the age-matched control rats (nontransgenic littermates) on the previous day. Every 2 weeks, another group of transgenic rats was subjected to subcutaneous implants of an hGH-containing powder kindly supplied by Takeda Chemical Industries Ltd (Osaka, Japan), which could constantly deliver hGH for 2 weeks, so that the serum hGH levels were maintained at around $50 \mathrm{ng} / \mathrm{ml}$ (see Results). Transgenic rats implanted with a powder without hGH served as a sham-implanted group. At the age of 12 weeks, all the animals were weighed and then killed by decapitation. Trunk blood was collected, and the serum was obtained by centrifugation and stored at $-20^{\circ} \mathrm{C}$ until assayed. In addition, the epididymal fat pad was dissected out and weighed.

\section{Assays}

Serum triglyceride concentration was determined by means of the glycerol-3-phosphate oxidase, N-(2hydroxy-3-sulfopropyl)-3,5-dimethoxyaniline, sodium salt (GPO-HDAOS) method using a commercial kit (Wako, Osaka, Japan). Serum FFA concentration was determined by means of an enzyme method using a commercial kit (Eiken, Tokyo, Japan). Serum insulin concentration was determined using a commercial enzyme immunoassay kit (Amersham Pharmacia Biotech, Amersham, Bucks, UK). Serum leptin concentration was determined using a commercial ELISA kit (Morinaga, Yokohama, Japan). All assays were performed in duplicate or triplicate.

\section{Statistics}

All the data were analyzed by means of ANOVA followed by Fisher's PLSD test, and the difference was considered significant at $P<0.05$.

\section{Results}

Since there were no differences between intact and sham-implanted transgenic rats in terms of any of the parameters examined, the data from both groups were combined in this study. The concentrations of 
serum hGH in intact and hGH-treated transgenic rats at the age of 12 weeks were $26.0 \pm 3.9$ and $48.8 \pm$ $6.9 \mathrm{ng} / \mathrm{ml}$ (means \pm s.E.M.) respectively $(P<0.05)$.

A group of transgenic rats was pair-fed in relation to age-matched control rats from 4 to 12 weeks of age. Figure 1A shows the mean amount of daily food intake during the last week of the experimental period. Food consumption of the transgenic rats was greater by $27 \%$ than that of control rats and hence that of the pair-fed transgenic rats. Body weight of the transgenic rats at 12 weeks of age was greater by $10 \%$ than that of controls, while that of pair-fed animals was even less than that of controls (Fig. 1B). Treatment with hGH affected neither food consumption nor body weight.

The weights of epididymal white adipose tissue (WAT) in the control and transgenic rats were 6.6士 0.6 and $18.8 \pm 1.1 \mathrm{~g}$ (means \pm S.E.M.) respectively. WAT weight to body weight (WAT/BW) ratio was more than three times greater in transgenic $(4.0 \%)$ than control rats $(1.2 \%)$. Although pair-feeding did not affect the WAT/BW ratio, hGH treatment reduced it by $30 \%$ (Fig. 2).

Serum concentrations of triglyceride, FFA, insulin and leptin were all significantly higher in the transgenic than in the control rats (Table 1). Pair-feeding was effective in reducing serum triglyceride, insulin and leptin levels, whereas it did not affect serum FFA levels in the transgenic rats. Treatment with hGH significantly reduced serum leptin concentrations in the transgenic rats, but it did not have this effect on other parameters.

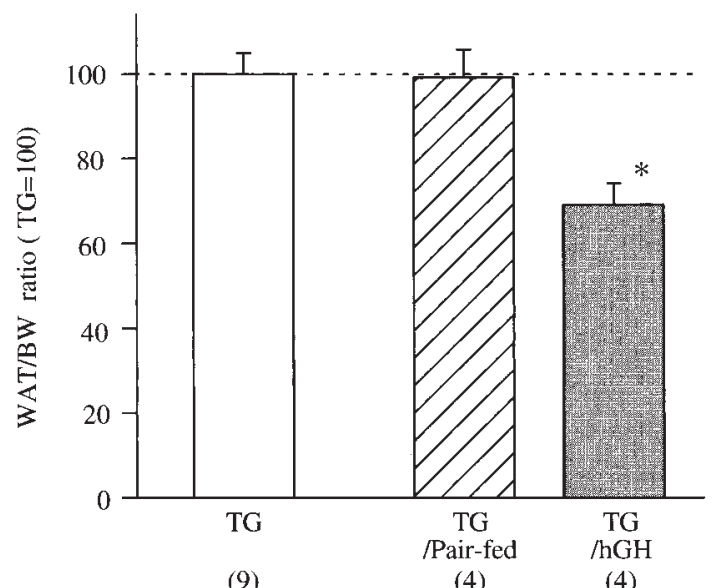

Figure 2 Changes of white adipose tissue/body weight (WAT/BW) ratio in pair-fed (TG/Pair-fed) and hGH-treated (TG/hGH) transgenic rats from that in intact transgenic rats (TG). WAT/BW ratio in the TG group is designated as 100. Numbers of animals used are given in parentheses. Data are expressed as means and S.E.M. ${ }^{*} P<0.05$ vs TG.

\section{Discussion}

The present study confirmed our previous finding (13) that the transgenic rats consumed more food than control rats. Although the body weight of the transgenic rats was greater than that of the control rats, the food intake to body weight ratio was still greater in transgenic than in control rats. The body weight of animals pair-fed for 8 weeks was even less than that of the control animals, suggesting that the transgenic rats require more calories to maintain their body weight. Despite the decrease in body weight, the WAT/BW ratio was not affected at all by pair-feeding. On the other hand, treatment with hGH for 8 weeks, which elevated serum hGH levels around twofold, decreased the WAT/BW ratio by $30 \%$ in the transgenic rats, though it did not affect food intake or body weight. Taken together, these results suggest that the severe fat accumulation observed in the transgenic rats can be attributed to the decrease in lipolytic action of $\mathrm{GH}$ rather than to enhanced caloric intake.

Obesity is frequently associated with insulin resistance. In fact, we previously demonstrated that insulin resistance occurred in our obese transgenic rats (12). The present study also demonstrated hyperinsulinemia and hyperlipidemia in the transgenic rats. Pair-feeding, but not hGH treatment, almost completely restored serum insulin levels. Since the increase in WAT mass remained even if the rats were pair-fed with controls, it is possible that increased insulin levels in the transgenic rats did not result only from fat accumulations. In contrast, although hGH treatment reduced WAT mass, it did not affect serum insulin levels. In the transgenic rats treated with hGH, the anti-insulin action of GH may at least partially account for their high serum insulin levels. From these results, we conclude that hyperinsulinemia in the transgenic rats was induced mainly to dispose of excess caloric intake and that fat accumulation itself played a minimal role in the development of insulin resistance. However, pairfeeding did reduce serum insulin levels. Whether or not it restored insulin resistance in the transgenic rats has yet to be elucidated.

Since the increased circulating triglyceride levels in transgenic rats were also restored by pair-feeding, but not by hGH treatment, hypertriglyceridemia in these rats could be explained by excessive caloric intake. However, pair-feeding did not affect serum FFA levels in the transgenic rats. One possible explanation for this result could be that there was no alteration of WAT mass in pair-fed transgenic rats, because it has been shown that circulating FFA concentration is well correlated with adipose tissue mass (15). On the other hand, although hGH treatment reduced fat accumulation in transgenic animals, it did not significantly affect serum FFA levels. Since it has been reported that $\mathrm{GH}$ treatment of obese subjects reduced fat accumulation and elevated circulating FFA levels 
Table 1 Effect of pair-feeding and hGH treatment on serum triglyceride, FFA, insulin and leptin concentrations. Values are means \pm S.E.M. with the numbers of animals in parentheses.

\begin{tabular}{|c|c|c|c|c|}
\hline & $\begin{array}{l}\text { Control } \\
(n=10)\end{array}$ & $\begin{array}{c}\text { TG } \\
(n=9)\end{array}$ & $\begin{array}{c}\text { TG/pair-fed } \\
(n=4)\end{array}$ & $\begin{array}{c}\text { TG/hGH } \\
(n=4)\end{array}$ \\
\hline Triglyceride (mg/dl) & $55.8 \pm 8.8$ & $234.9 \pm 45.1^{\mathrm{a}}$ & $27.5 \pm 0.5^{b}$ & $199.5 \pm 23.7^{a}$ \\
\hline FFA $(m E q / l)$ & $0.88 \pm 0.09$ & $1.34 \pm 0.16^{\mathrm{a}}$ & $1.80 \pm 0.01^{a}$ & $0.99 \pm 0.04^{a}$ \\
\hline Insulin (ng/ml) & $5.9 \pm 0.7$ & $19.6 \pm 1.3^{\mathrm{a}}$ & $5.3 \pm 1.3^{b}$ & $23.1 \pm 2.5^{\mathrm{a}}$ \\
\hline Leptin (ng/ml) & $5.8 \pm 0.8$ & $17.6 \pm 2.2^{\mathrm{a}}$ & $7.1 \pm 0.5^{b}$ & $10.9 \pm 1.4^{\mathrm{a}, \mathrm{b}}$ \\
\hline
\end{tabular}

(5), FFA levels in the hGH-treated groups may have been a consequence of lipolysis by hGH.

Circulating leptin levels have been shown to correlate with specific estimates of body fat $(16,17)$, and obese subjects have increased leptin concentrations, which could be reduced by treatment of the obesity. In obese individuals, however, their high plasma leptin levels do not induce the anticipated responses, and this phenomenon has led to the concept of leptin resistance (18). We previously reported that the transgenic rats suffer from leptin resistance as well as hyperleptinemia (13). In the present study, pair-feeding almost completely restored serum leptin levels, though it did not affect WAT mass. It has been reported that treatment of adipocytes with insulin enhanced leptin secretion $(19,20)$ and that circulating leptin levels were decreased by fasting with decreased insulin levels (21). These findings suggest that the decrease in serum leptin levels in pair-fed transgenic rats was attributable to low serum insulin levels. On the other hand, hGH treatment partially restored serum leptin levels without affecting serum insulin levels. In GHD adults, increased circulating leptin levels have previously been observed $(22,23)$ and could be reduced by $\mathrm{GH}$ therapy. Under in vitro experimental conditions, GH does not affect leptin expression or secretion (24) and, therefore, it is likely that leptin levels in GHD adults reflect body composition rather than $\mathrm{GH}$ status. Taken together, these findings indicate that the decrease in WAT mass might be a primary cause of the decrease in serum leptin levels in hGH-treated rats.

It has been recognized that a deficiency in $\mathrm{GH}$ induces an increase in insulin sensitivity. In fact, the occurrence of fasting hypoglycemia has been demonstrated in GHD children (25) and adults (26). This notion has been further supported by studies using animal models such as dwarf rats (27) and GH receptorknockout mice (28). On the other hand, several researchers have recently reported that insulin resistance occurs in GHD subjects. For example, Cuneo et al. (29) reported increased fasting insulin levels in GHD adults. Decreased insulin sensitivity has also been shown in GHD adults by mean of the euglycemichyperinsulinemic clamp method $(30,31)$. The observations of the present study could account for this discrepancy, i.e. circulating insulin levels in GHD subjects might depend on individual caloric intake. Further studies on the relationship between energy balance and insulin sensitivity in GHD subjects are needed to clarify this problem.

In conclusion, the results of the present study suggest that severe fat accumulation in the transgenic rats mainly resulted from the decreased lipolytic action of $\mathrm{GH}$, while hyperinsulinemia resulted mainly from enhanced caloric intake. The leptin resistance demonstrated in our previous study (13) may have been at least partially involved in the hyperphagia of the transgenic rats. The present study may help in understanding in cases of insulin resistance under GHD.

\section{Acknowledgements}

This work was supported by 'Research for the Future' Program, the Japan Society for the Promotion of Science (JSPS-RFTF 97L00904). YF is a research fellow of the Japan Society for the Promotion of Science.

\section{References}

1 Davidson MB. Effect of growth hormone on carbohydrate and lipid metabolism. Endocrine Reviews 19878 115-131.

2 de Boer H, Blok GJ \& Van der Veen EA. Clinical aspects of growth hormone deficiency in adults. Endocrine Reviews 199516 63-86.

3 Salomon F, Cuneo RC, Hesp R \& Sonksen PH. The effects of treatment with recombinant human growth hormone on body composition and metabolism in adults with growth hormone deficiency. New England Journal of Medicine 1989321 1797-1803.

4 Bengtsson BA, Eden S, Lonn L, Kvist H, Stokland A, Lindstedt G et al. Treatment of adults with growth hormone $(\mathrm{GH})$ deficiency with recombinant human GH. Journal of Clinical Endocrinology and Metabolism 199376 309-317.

5 Richelsen B, Pedersen SB, Borglum JD, Moller-Pedersen T, Jorgensen J \& Jorgensen JO. Growth hormone treatment of obese women for $5 \mathrm{wk}$ : effect on body composition and adipose tissue LPL activity. American Journal of Physiology 1994266 E211-E216.

6 Snyder DK, Clemmons DR \& Underwood LE. Treatment of obese, diet-restricted subjects with growth hormone for 11 weeks: effects on anabolism, lipolysis, and body composition. Journal of Clinical Endocrinology and Metabolism 198867 54-61.

7 Turner ND, Knapp JR, Byers FM \& Kopchick JJ. Expression of mutant bovine growth hormone genes in mice perturbs agerelated nutrient utilization patterns. Journal of Nutrition 1998 $128520-524$. 
8 Levin N, Nelson C, Gurney A, Vandlen R \& de Sauvage F. Decreased food intake does not completely account for adiposity reduction after ob protein infusion. PNAS 199693 1726-1730.

9 Veldhuis JD, Iranmanesh A, Ho KK, Waters MJ, Johnson ML \& Lizarralde G. Dual defects in pulsatile growth hormone secretion and clearance subserve the hyposomatotropism of obesity in man. Journal of Clinical Endocrinology and Metabolism 199172 $51-59$.

10 Renier G, Gaudreau P, Hajjad H, Deslauriers N, Houde-Nadeau M \& Brazeau P. Decreased pituitary growth hormone response to growth hormone-releasing factor in cafeteria-fed rats: dietary and obesity effects. Neuroendocrinology $1990 \mathbf{5 2} 284-290$.

11 Rasmussen MH, Hvidberg A, Juul A, Main KM, Gotfredsen A, Skakkebaek NE et al. Massive weight loss restores 24-hour growth hormone release profiles and serum insulin-like growth factor-I levels in obese subjects. Journal of Clinical Endocrinology and Metabolism $1995 \mathbf{8 0} 1407-1415$.

12 Ikeda A, Chang KT, Matsumoto Y, Furuhata Y, Nishihara M, Sasaki F et al. Obesity and insulin resistance in human growth hormone transgenic rats. Endocrinology $19981393057-3063$.

13 Furuhata Y, Kagaya R, Hirabayashi K, Ikeda A, Chang KT, Nishihara $\mathrm{M}$ et al. Development of obesity in transgenic rats with low circulating growth hormone level: involvement of leptin resistance. European Journal of Endocrinology 2000143 535-541.

14 Ikeda A, Matsuyama S, Nishihara M, Tojo H \& Takahashi M. Changes in endogenous growth hormone secretion and onset of puberty in transgenic rats expressing human growth hormone gene. Endocrine Journal $199441523-529$.

15 Bjarnason R, Boguszewski M, Dahlgren J, Gelander L, Kristrom B, Rosberg $\mathrm{S}$ et al. Leptin levels are strongly correlated with those of GH-binding protein in prepubertal children. European Journal of Endocrinology $1997 \mathbf{1 3 7} 68-73$.

16 Hickey MS, Israel RG, Gardiner SN, Considine RV, McCammon MR, Tyndall GL et al. Gender differences in serum leptin levels in humans. Biochemical and Molecular Medicine 199659 1-6.

17 Rosenbaum M, Nicolson M, Hirsch J, Heymsfield SB, Gallagher D, Chu F et al. Effects of gender, body composition, and menopause on plasma concentrations of leptin. Journal of Clinical Endocrinology and Metabolism $1996813424-3427$.

18 Caro JF, Sinha MK, Kolaczynski JW, Zhang PL \& Considine RV. Leptin: the tale of an obesity gene. Diabetes $1996 \mathbf{4 5} 1455-1462$.

19 Cusin I, Sainsbury A, Doyle P, Rohner-Jeanrenaud F \& Jeanrenaud B. The ob gene and insulin. A relationship leading to clues to the understanding of obesity. Diabetes $1995 \mathbf{4 4} 1467-1470$.

20 Saladin R, De Vos P, Guerre-Millo M, Leturque A, Girard J, Staels B et al. Transient increase in obese gene expression after food intake or insulin administration. Nature 1995377 527-529.
21 Trayhurn P, Hoggard N, Mercer JG \& Rayner DV. Leptin: fundamental aspects. International Journal of Obesity and Related Metabolic Disorders $19992322-28$.

22 Bjorntorp P, Bergman H, Varnauskas E \& Lindholm B. Lipid mobilization in relation to body composition in man. Metabolism: Clinical and Experimental 196918 840-851.

23 Fisker S, Vahl N, Hansen TB, Jorgensen JO, Hagen C, Orskov H et al. Serum leptin is increased in growth hormone-deficient adults: relationship to body composition and effects of placebocontrolled growth hormone therapy for 1 year. Metabolism: Clinical and Experimental $1997 \mathbf{4 6} 812-817$.

24 Hardie LJ, Guilhot N \& Trayhurn P. Regulation of leptin production in cultured mature white adipocytes. Hormone and Metabolic Research $1996 \mathbf{2 8} 685-689$.

25 Wolfsdorf JI, Sadeghi-Nejad A \& Senior B. Hypoketonemia and age-related fasting hypoglycemia in growth hormone deficiency. Metabolism: Clinical and Experimental 198332 457-462.

26 Merimee TJ, Felig P, Marliss E, Fineberg SE \& Cahill GG Jr. Glucose and lipid homeostasis in the absence of human growth hormone. Journal of Clinical Investigation 197150 574-582.

27 Daugaard JR, Laustsen JL, Hansen BS \& Richter EA. Insulin action in growth hormone-deficient and age-matched control rats: effect of growth hormone treatment. Journal of Endocrinology $1999 \mathbf{1 6 0}$ $127-135$.

28 Dominici FP, Arostegui Diaz G, Bartke A, Kopchick J \& Turyn D. Compensatory alterations of insulin signal transduction in liver of growth hormone receptor knockout mice. Journal of Endocrinology $2000166579-590$.

29 Cuneo RC, Salomon F, McGauley GA \& Sonksen PH. The growth hormone deficiency syndrome in adults. Clinical Endocrinology $199237387-397$.

30 Johansson JO, Fowelin J, Landin K, Lager I \& Bengtsson BA. Growth hormone-deficient adults are insulin-resistant. Metabolism: Clinical and Experimental $1995441126-1129$.

31 Hew FL, Koschmann M, Christopher M, Rantzau C, Vaag A, Ward $\mathrm{G}$ et al. Insulin resistance in growth hormone-deficient adults: defects in glucose utilization and glycogen synthase activity. Journal of Clinical Endocrinology and Metabolism $1996 \mathbf{8 1}$ 555-564.

Received 12 July 2001

Accepted 2 October 2001 